\title{
Reconstruction of Sea Surface Temperatures in Holocene Times: Coral- Based Studies in the Red Sea and the Western Indian Ocean
}

Sea Surface Temperature (SST) is an important factor for the reconstruction of global climate change. SST influences physical parameters like ocean-atmosphere gas exchange, global precipitation patterns, sealevel, ocean circulation and the influence of climate teleconnections (e.g. Monsoon and El Nino events) (Gagan et al. 1994, Klein et al. 1997, Eisenhauer et al. in press).

Corals from modern and fossil reefs from tropical and subtropical oceans provide an important paleoclimate archive. The skeletons of reef-building corals contain isotopic and chemical tracers that record water temperature and salinity (evaporation/ rainfall). Massive corals produce annual density bands that can be used for the development of chronologies (e.g., Dunbar \& Cole, 1999). Coral records are highly useful for the reconstruction of past climate variability at seasonal to multidecadal time scales. Modern corals provide climate records extending back several hundred years. Accurately dated fossil corals provide information on climate variability during time-windows throughout the late Quaternary (e.g., Dunbar \& Cole, 1999).

Red Sea corals provide an opportunity for annual- to seasonal-resolution paleoclimatic reconstructions from the African-Asian desert belt. Recent coral-based studies as part of the "Red Sea Program” (RSP), funded by the German Federal Ministry for Education and Research (BMBF), have provided important information on past climate and ocean variability in the northern Red Sea at seasonal to multidecadal time scales. Examples include the prominent influence of the North Atlantic Oscillation, the El Niño-Southern Oscillation, and North Pacific climate variability during the past $\sim 250$ years (Felis et al., 1999); the documentation of vertical water mass mixing events which are sometimes associated with large volcanic eruptions (Felis et al., 1998); and a possible influence of summer monsoon rains during the mid-Holocene on this area (Moustafa et al., in press).

Recent studies include coral isotopic records from the Seychelles which display annual to decadal scale climate

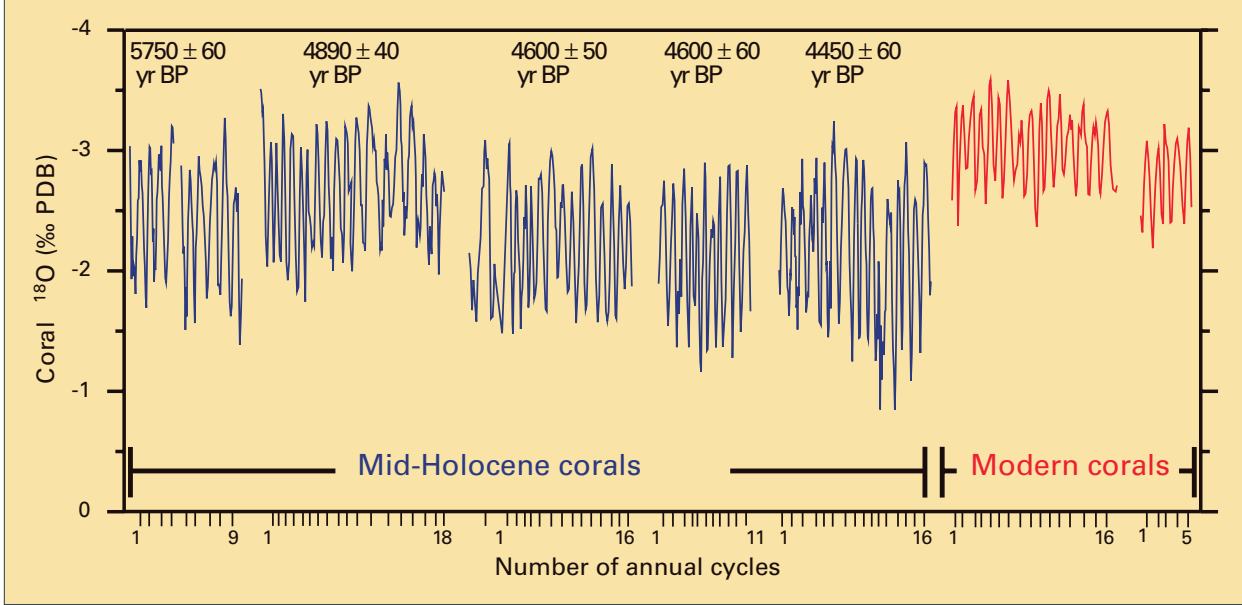

Figure 1: Stable oxygen isotope time series of fossil mid-Holocene (4450-5750 ${ }^{14} \mathrm{C}$ years BP) and modern corals from the northern Red Sea (Eilat, Gulf of Aqaba, 29 $31^{\prime} N / 34^{\circ} 56^{\prime} E$ ). Compared with modern corals from the same location the average seasonal amplitude of the fossil corals is higher. This suggests stronger seasonality of the sea surface temperature and increased variability of the oxygen isotopic composition of the sea water due to changes in the precipitation and evaporation regime during the mid-Holocene. From Moustafa et al., in press 2000, Int. Journ. Earth Sciences; data of modern corals from Klein et al.,1992, Mar. Biol., 112, 259-263, and Felis et al., 1998, J. Geophys. Res., 103, 30731-30739.

oscillations. Spectral analysis reveals interannual cycles in the El-Niño frequency band, with a period of 3 to 5 years. Furthermore, these tropical records are clearly dominated by decadal scale cycles, with a period of approximately 12 years. As suggested by Charles et al. (1997), the decadal mode appears to be characteristic of the Asian Monsoon system: negative $\delta^{18} \mathrm{O}$ anomalies (warm SST) correspond to a weak monsoon, and positive $\delta^{18} \mathrm{O}$ anomalies (cool SST) represent a strong monsoon.

Although the $\delta^{18} \mathrm{O}$-method for reconstructing SST is quite successful, its application is limited due to the influence of precipitation/evaporation changes and variations of continental ice volume. Thus, independent SST proxies like $\mathrm{Sr} / \mathrm{Ca}, \mathrm{Mg} / \mathrm{Ca}$ and alkenones are highly desirable. Chemical SST-proxies like Sr/Ca (Beck et al. 1992) are supposed to be independent of precipitation/ evaporation, however, there are still uncertainties because of species dependent SST-Sr/Ca calibration (De Villiers et al. 1984, 1985). On Holocene and Late Pleistocene time scales $\mathrm{Sr} / \mathrm{Ca}$ is limited due to diagenetic alterations of the aragonite skeleton. It has been found that secondary aragonite tends to be enriched in $\mathrm{Sr} / \mathrm{Ca}$ resulting in SST estimeates that are lower than those derived from other proxies. This challenges the predicted 5 to $6^{\circ} \mathrm{CSST}$ difference (Beck et al. 1992) between Holocene and Last Glacial Maximum (LGM) and lends further support to earlier findings that tropical SST variations in the tropics are in the order of 2 to $3^{\circ} \mathrm{C}$ (CLIMAP 1981).

The subtropical setting of the Red Sea provides the opportunity to study the interaction between extratropical and tropical modes of climate variability during the Holocene in this region. Further work on fossil and modern corals from this region and the Western Indian Ocean carried out jointly by the University of Bremen and GEOMAR in Kiel, will continue as part of the project „Natural climate variations from 10,000 years to the present day" (Klima in historischen Zeiten, KIHZ, see also PAGES Newsletter 99-3), funded by the Helmholtz Association of National Research Centers (HGF) and the BMBF. This project provides a link between the efforts of both National Research Centers and universities in Germany in studying the dynamics of natural climate variability. Sub-annual-resolution paleoclimatic records derived from fossil Red Sea corals will be compared to those derived from modern corals growing at the same location. These high-resolution marine records will help to pro- 
vide a link to terrestrial limnic records as derived from varved evaporitic sediments of the Dead Sea to the north (e.g., Heim et al., 1997) but also to other marine records as derived from varved oxygenminimum-zone sediments of the Arabian Sea to the south (von Rad et al., 1999) which documents variations in the intensity of the Asian monsoon. The coral-based paleoclimatic records will also support terrestrial reconstructions and model simulations of Holocene climate variability in the Saharan and Arabian region (e.g., Hoelzmann et al., 1998; Claussen et al., 1999). Furthermore, the studies will contribute to other paleoenvironmental research along the PAGESPole-Equator-Pole transect which passes through Europe and Africa (PEP III) (Gasse et al., 1997).

\section{References}

Beck, J.W. et al. 1992. Science, 257, 644-647.

Claussen, M. et al. 1999. Geophys. Res. Lett., 26, 2037-2040.

CLIMAP 1981. GSA Map and Chart Ser. MC-36. Boulder, CO. Geol. Soc. of Am.

DeVilliers, S. et al. 1994. Geochim. Cosmochim. Acta, 58, 197-208.

DeVilliers, S. et al. 1995. Science, 269, 1247-1249.

Dunbar, R.B. \& Cole, J.E. 1999. Annual Records of Tropical Systems (ARTS). PAGES Workshop Report 99-1, 72 pp.

Eisenhaver, A., et al. Chemical Geology, in press.

Felis, T.et al. 1998. J. Geophys. Res., 103,

30731-30739.

Felis, T. et al. 1999. AGU, 80(46) Fall Meet. Suppl., F575.

Gagan, M. K. et al. 1994. Earth Planet. Sci. Lett., 121, 549-558.

Gasse, F. et al. 1997. PEP III: The Pole-Equator-Pole transect through Europe and Africa. PAGES Workshop Report 97-2, 64 pp.

Heim, C. et al.1997. Naturwissenschaften, 84, 398-401.

Hoelzmann, P. et al. 1998. Global Biogeochem. Cycles, 12, 35-51.

Klein, R. et al.1997. Earth Planet. Sci. Lett.,148, pp. 381-394.

Moustafa, Y. A. et al. 2000. Int. Journ. Earth Sciences, in press.

von Rad, U. et al. 1999. Quat. Res., 51, 39-53.

\section{Jürgen Pätzold}

Fachbereich Geowissenschaften, Universität Bremen, Germany

juergen.paetzold@uni-bremen.de

\section{Christian Dullo}

GEOMAR Forschungszentrum Kiel, Germany

cdullo@geomar.de

\section{Late-Glacial and Early-Holocene Climate Reconstructions at Kråkenes Lake, a West Norwegian Point on PEP III}

Terrestrial plants and animals respond directly to climatic change when their tolerance thresholds are crossed. However, organisms are not independent like physical measurements but interact in ecosystems where feedbacks apply according to their physiological and ecological tolerances and their population structure (including their biogeography). Ecosystem stability is ultimately controlled by climate, so organisms still show a climatic signal. The signals can be quantified by relating modern organism assemblages to climate (or any measured environmental variable) as a calibration (transfer) function which can then be used to reconstruct quantitatively the past environmental parameters from fossil assemblages. For Europe climate calibration functions currently exist for pollen, Chironomidae, Cladocera, diatoms, and Coleoptera. Indicator species and analogue (assemblage) approaches (e.g. plant macrofossils) can also be used to make quantitative paleoclimatic reconstructions.

For calculation of the magnitudes and rates of past climatic change, multi-proxy studies from high-resolution sequences with calendar chronologies are needed. One such study is the recently completed Kråkenes Project (Kråkenes Project, 2000; Birks et al., 1996; Birks \& Wright, 2000). To detect regional patterns in past climatic change, a comprehensive array of sites is needed covering critical climatic and vegetational boundaries (ecotones), for example the PEP III transect for which the Kråkenes Project results in western Norway comprise an important reference point for the late-glacial and early Holocene. This note briefly presents some climatic conclusions of the Kråkenes Project and shows how multi-proxy biotic responses utilising the sensitivity of organisms to climate at terrestrial sites can be used to reconstruct late-glacial temperature values and the magnitudes and rates of temperature change. It demonstrates the potential of terrestrial sites and organisms for paleoclimatic reconstruction using modern paleoclimatic approaches on fossil organisms.

Kråkenes Lake is exceptional in western Norway because it was deglaciated during the Allerød period (ca. 14,000 cal
BP) but a cirque glacier developed in its catchment during the Younger Dryas and deposited glacio-lacustrine sediments in the lake (Birks et al., 1996, Gulliksen et al., 1998). The Kråkenes Project mostly utilised a single sediment core covering the late-glacial and early-Holocene periods. The rapid sedimentation rates and the abundance of Salix herbacea leaves in the sediments have allowed a high-resolution ${ }^{14} \mathrm{C}$ date series to be made using terrestrial plant macrofossils and earlyHolocene lake sediment $\left(12,300-8000{ }^{14} \mathrm{C}\right.$ yr BP) that has been calibrated to produce a calendar-year chronology $(14,000-9000$ cal BP) (Gulliksen et al., 1998; Birks et al., 2000). The multi-disciplinary project uses plant macrofossils, pollen, mosses, diatoms, oribatid mites, Chironomidae, Cladocera, Coleoptera, and Trichoptera to reconstruct the ecosystem development and the magnitudes and rates of temperature changes and biotic responses round the Younger Dryas.

The Kråkenes lacustrine sequence was strongly influenced by the development of the Younger Dryas glacier. Temperature rather than precipitation controlled the glacier changes and the biotic responses. Temperature also controlled the initial development at the start of the Holocene, but as it continued to rise over time, ecosystem feedback processes became influential (Birks et al., 2000). Terrestrial and aquatic organisms all reacted rapidly to the large late-glacial climatic changes (at least as fast as the changes registered in ice cores), showing that they are sensitive climatic indicators and are sufficiently mobile to move quickly to new suitable habitats. Species responded individualistically, but in periods of strong, fast climatic changes their responses were telescoped together and altered the whole ecosystem. During more gradual climatic changes (Holocene warming) the individualistic responses were expressed, leading to variable rates of change related to ecosystem changes linked to environmental and catchment feedbacks and climatic thresholds.

Quantitative mean July temperature reconstructions made using different groups and methods are plotted against the calibrated chronology in Fig. 1 (Birks \& 